\title{
Synergistic Therapeutic Strategy of Dual Drug-loaded Lipid Polymer Hybrid Nanoparticles for Breast Cancer Treatment
}

\author{
T. H. TRAN ${ }^{1}$, H. T. NGUYEN², C. S. YONG ${ }^{2}$, D. H. TRUONG ${ }^{3}$, J. O. KIM²* \\ Department for Management of Science and Technology Development, ${ }^{1}$ Faculty of Pharmacy, Ton Duc Thang University, Ho \\ Chi Minh City, Vietnam, ${ }^{2}$ College of Pharmacy, Yeungnam University, 214-1, Dae-Dong, Gyeongsan 712-749, South Korea, \\ ${ }^{3}$ Institute of Research and Development, Duy Tan University, 03 Quang Trung, Da Nang, Vietnam
}

Tran et al.: Dual Drug-loaded Lipid Polymer Hybrid Nanoparticles

\begin{abstract}
In this investigation, a smart nanocarrier-loaded docetaxel, a microtubules disrupting agent and vorinostat, a histone deacetylase inhibitor was developed to achieve a synergistic anticancer effect. Dual drug-loaded lipid polymer hybrid nanoparticles were prepared, with easy fabrication and favourable properties including small size, narrow distribution and a high loading efficacy. The in vitro drug release conducted in phosphatebuffered saline, pH 7.4 and acetate-buffered saline, pH 5.5 media demonstrated the sustained, pH-dependent release profile. The nanoparticles were effectively taken up by cells, which ensured greater suppression of cell growth. The co-delivery of both drugs exhibited a synergistic effect on the induction of cancer cell apoptosis, resulting in greater inhibition of SCC-7, MCF-7, and MDA-MB-231 cancer cells by the drug-loaded carrier. These promising results may lead to clinical applications with enhanced docetaxel activity.
\end{abstract}

Key words: Docetaxel, vorinostat, combination therapy, lipid carrier, pH sensitive polymer

With an estimated 1.67 million new cases diagnosed in 2012, breast cancer is considered to be the second most common cancer type in the world. In terms of abnormal cell growth, it presents the most severe threat to women ${ }^{[1,2]}$. One treatment strategy is chemotherapy with docetaxel (DTX, Taxotere ${ }^{\circledR}$ ), the most common anticancer drug used against breast cancer ${ }^{[3,4]}$. DTX has been reported to induce cell cycle arrest and apoptosis through binding and inhibition of the depolymerisation of the $\alpha$-tubulin subunit of microtubules ${ }^{[5]}$. Although it has contributed greatly to antibreast cancer therapies, resistance to DTX has become a risk to patients ${ }^{[6,7]}$. Among the many strategies to overcome this drawback, combinatorial formulations, with the co-delivery of two drugs, have been successfully developed to reverse multiple drug resistance in in vitro as well as in vivo cancer models ${ }^{[8-10]}$. In case of DTX, Shi et al. investigated a combination with vorinostat (VRS), a histone deacetylase inhibitor, to enhance cell death in breast cancer ${ }^{[11]}$. In detail, VRS enhanced the DTX-induced G2/M arrest in breast cancer MDAMB-231 cells whereas the expression of cell cycle and apoptosis-associated proteins in MDA-MB-231 cells are noticed to be changed in association with VRS/

*Address for correspondence E-mail: jongohkim@yu.ac.kr

May-June 2019
DTX treatments. The alteration of gene expression through DNA methylation and histone modification is considered to be a cause of resistance to DTX in cancer $^{[12]}$ where histone deacetylase inhibitors fill the gap for improving cancer treatment. In addition, treatment with VRS has also been shown to increase the cytotoxicity of various therapeutic agents, including Taxol, through the relaxation of the chromatin structure and an increase in the sensitivity of a drug to its DNA target ${ }^{[13]}$.

Despite the enhancement of therapeutic efficacy, combinational strategies are challenged by a variety of different drug pharmacokinetics, which may end up with an inconsistent drug uptake and suboptimal drug combination at the tumor sites. In the last decade, nanoparticles drew a great attention not only for efficacy improvement but also for restriction of

This is an open access article distributed under the terms of the Creative Commons Attribution-NonCommercial-ShareAlike 3.0 License, which allows others to remix, tweak, and build upon the work non-commercially, as long as the author is credited and the new creations are licensed under the identical terms

Accepted 02 April 2019

Revised 10 December 2018

Received 21 August 2018

Indian J Pharm Sci 2019;81(3):474-482 
drawback such as experimental multidrug resistant or administration variety ${ }^{[9]}$. Methoxy-poly(ethylene glycol)-block-poly(L-aspartic acid) (PEG-b-PAsp) is a linear amphiphilic block co-polymer able to self-assemble into nanoparticles with a hydrophobic poly(L-aspartic acid) core and a hydrophilic PEG shell[14,15]. Owing to the protonation of the carboxylic group at low $\mathrm{pH}$, anionic poly(L-aspartic acid) has been studied as potential $\mathrm{pH}$-sensitive drug carrier ${ }^{[16,17]}$. The combination of this polyelectrolyte block copolymer on the surface of nanoparticles could be potential to boost the drug release in the acidic environment found in the endosomes of cancer cells ${ }^{[15,16,18-20]}$. Furthermore, the PEG shell could enable prolonged blood circulation and avoid the rapid elimination of nanoparticles ${ }^{[21,22]}$.

In this work, both drugs were incorporated into the lipid core of a smart carrier, which was designed to revert from a favourable negative charge into a positive charge in acidic environment to improve binding of nanoparticles to the surface of cancer cells. The dynamic properties of carriers including particle size and morphology were characterized using dynamic light scattering (DLS) and transmission electron microscopy (TEM), respectively. In vitro drug release was evaluated to assess the dissolution rate of both drugs into different conditions. In addition, intracellular uptake was analysed using confocal imaging and flow cytometry and the in vitro cytotoxicity was conducted to check the activities of the drugs in single or combination. Finally, apoptosis studies were conducted to provide stronger evidence using nanoparticle-based combination therapy for the treatment of breast cancer.

\section{MATERIALS AND METHODS}

DTX and VRS were purchased from LC Laboratories (MA, USA). Capryol 90 (Capryol) was from Gattefosse (Cedex, France). Coumarin-6 and Hoechst 33342 were purchased from Thermo Fisher Scientific (Waltham, MA, USA). 3-(4,5-Dimethylthiazol-2yl)-2,5-diphenyl-tetrazolium bromide (MTT) and didecyldimethylammonium bromide (DDAB) were obtained from Sigma (St. Louis, MO, USA). D- $\alpha-$ tocopherol polyethylene glycol 1000 succinate (TPGS) was supplied by Isocheim (Vert le Petit, France). PEGb-PAsp (MW: 12 000) was purchased from Alamanda Polymers (Huntsville, AL, USA). All other chemicals were of reagent grade and were used without further purification.

All cell lines were cultured in Roswell Park Memorial Institute-1640 medium supplemented with $10 \%$ fetal bovine serum and $1 \%$ penicillin-streptomycin (Hyclone Laboratories, Logan, UT, USA), respectively. Cells were maintained at $37^{\circ}$ in an atmosphere of $5 \% \mathrm{CO}_{2}$. The squamous cell carcinoma (SCC-7), human breast adenocarcinoma (MCF-7), and human Caucasian breast adenocarcinoma (MDA-MB-231) cells were originally obtained from the Korean Cell Line Bank (Seoul, South Korea).

\section{Preparation of lipid polymer hybrid nanoparticles:}

The modified emulsification method was used to fabricate lipid polymer hybrid nanoparticles (LPHs) ${ }^{[23]}$. Briefly, VRS and DTX were dissolved in melted lipid mixture consisted of Capryol 90, TPGS, DDAB in the ratio of 3:1:0.05. Then lipid solution was homogenously dispensed into $2 \mathrm{mg} / \mathrm{ml}$ PEG- $b$-PAsp solution using Ultra Turrax ${ }^{\circledR}$ T-25 homogenizer (IKA ${ }^{\circledR}$ Werke, Staufen, Germany) for 3 min at $13500 \mathrm{rpm}$. The sonication process at $90 \%$ amplitude was applied to above dispersion using a high-intensity probe sonicator (Vibracell VCX130; Sonics, Newtown, CT, USA) for $5 \mathrm{~min}$. The final suspension was purified by using a centrifugal tube (molecular weight cut-off $30 \mathrm{kDa}$ ) after cooling on ice.

\section{Lyophilization of LPHs:}

The LPHs dispersion was lyophilized using mannitol as a cryoprotectant (FDA5518, IlShin, South Korea). Before lyophilization, the dispersion was frozen at $-20^{\circ}$ for $3 \mathrm{~h}$ before further freezing at $-80^{\circ}$ overnight. Lyophilization was conducted at a temperature of $-25^{\circ}$ for $24 \mathrm{~h}$, followed by a secondary drying phase for $12 \mathrm{~h}$ at $20^{\circ}$.

\section{Physical characterization of nanoparticles:}

A Zetasizer Nano-ZS90 was used to measure the particle size and zeta-potential of the nanoparticles. The formulation was diluted by distilled water prior to three replicate measurements. After negative staining dispersion with $2 \%(\mathrm{w} / \mathrm{v})$ phosphotungstic acid, nanoparticles were placed into copper grid and observed by TEM (H7600, Hitachi, Tokyo, Japan) ${ }^{[24]}$.

To determine the quantity of drugs encapsulated in LPHs, an Amicon centrifugal ultrafiltration device (MWCO $10 \mathrm{kDa}$, Millipore, Billerica, MA, USA) was used to separate dispersion. The centrifugation was introduced for $15 \mathrm{~min}$ at $5000 \mathrm{rpm}$. The free drug in the bottom chamber of the device was collected and evaluated by using HPLC (Hitachi Ltd., Tokyo, Japan) with a UV/Vis detector (model L-2420). Each drug was 
analysed individually, DTX was eluted using a mobile phase (acetonitrile and phosphate buffer $(\mathrm{pH}=3)$ at a volume ratio of 60/40) and detected at wavelength of $232 \mathrm{~nm}^{[25]}$ and for VRS, the mobile phase consisted of formic acid $(0.1 \%)$ /acetonitrile $(60 / 40)$ and the detection wavelength was $241 \mathrm{~nm}^{[26]}$.

To depict the crystal pattern of samples, the $\mathrm{CuK}_{\alpha}$ radiation source of X-ray diffractometer (X'Pert PRO MPD; PANalytical, Almelo, the Netherlands) was used to generate $\mathrm{X}$-ray laser with a voltage of $40 \mathrm{kV}$, a current of $30 \mathrm{~mA}$, and a scan step size of 0.02 . The measurement was conducted three times; a representative pattern is shown ${ }^{[27]}$.

The in vitro drug release study was conducted in two different $\mathrm{pH}$ conditions (phosphate-buffered saline, $\mathrm{pH} 7.4$ and acetate-buffered saline, $\mathrm{pH}$ 5.5) under sink conditions at $37^{\circ}$. Two millilitres of formulation were added into dialysis membrane tubing (Spectra/Por; $3.5 \mathrm{kDa}$ cutoff, CA, USA) and placed in $35 \mathrm{ml}$ of release medium. At predetermined intervals, $0.5 \mathrm{ml}$ samples of the release medium were withdrawn and another $0.5 \mathrm{ml}$ fresh medium was subsequently added to maintain the volume. The drug in the release medium was quantified by the HPLC method as described above $\mathrm{e}^{[14,28]}$.

\section{In vitro anticancer activity of nanoparticles:}

Flow cytometry was used to examine the cellular uptake of LPHs. Coumarin-6, a fluorescent dye, was incorporated into LPHs to observe the internalization in SCC-7, MDA-MB-231 and MCF-7 cell lines. For this, cells were seeded in 12-well plates at the rate of $10 \times 10^{4}$ cells per well and incubated overnight. Subsequently, the cells were treated with Cou6-LPHs at different concentrations and incubation times. The cells were then trypsinised, collected, and suspended in flow cytometry buffer. The fluorescent intensity of the particles taken up was detected by using a FACSVerse flow cytometer (BD Biosciences, San Jose, CA, USA) ${ }^{[29,30]}$.

The MTT assay was utilized to examine the toxicity of single drugs, combination drug, and formulations in cancer cell lines ${ }^{[7,31]}$. Cells were seeded in each well $\left(5 \times 10^{3}\right.$ cells/well $)$ of a 96 -well plates and grown overnight. The cells were then treated with free VRS, free DTX, the combination of free VRS and DTX, and VRS/DTX-LPH for $24 \mathrm{~h}$. Drug-containing media were aspirated carefully and replaced with fresh growth media containing MTT solution $(1.25 \mathrm{mg} / \mathrm{ml})$; subsequently, the cells were incubated for a further period of $3 \mathrm{~h}$. The crystals in each well was dissolved in $100 \mu \mathrm{DMSO}$ and the absorbance was measured using a microplate reader at $570 \mathrm{~nm}$ (Multiskan EX, Thermo Scientific, Waltham, MA, USA). Cell viability was calculated from the following formula, cell viability $(\%)=\left[\mathrm{OD}_{570}(\right.$ sample $)-\mathrm{OD}_{570}($ blank $\left.)\right] /\left[\mathrm{OD}_{570}(\right.$ control $)-$ $\mathrm{OD}_{570}$ (blank) $] \times 100$.

CalcuSyn software (Biosoft, Cambridge, UK) was used to calculate combination index based on the medianeffect principle for each combination corresponding to the cell viability from the MTT assay. Additivity, synergy, and antagonism were assigned according to $\mathrm{CI}$ values of $1.0,<1.0$, and $>1.0$, respectively ${ }^{[32,33]}$.

Induction of apoptosis in cells treated with drugs was determined using the Annexin-FITC/PI kit, which classifies the cells into four quadrants; subsequently, the percentages of early apoptotic cells (FITC positive/ PI negative), late apoptosis (FITC/PI positive), and necrotic (FITC negative/PI positive) were calculated. For sample preparation, a 6 -well plate containing $1 \times 10^{5}$ cells/well was incubated for $24 \mathrm{~h}$. Afterwards, each well was treated with the individual formulations, including free VRS, free DTX, free VRS/DTX combination, and VRS/DTX-LPH for $24 \mathrm{~h}$ at a concentration of $20 \mu \mathrm{M}$. The treated cells were harvested and rinsed before dispersing in $100 \mu \mathrm{l}$ binding buffer and stained with PI $(10 \mu \mathrm{l}, 1 \mathrm{mg} / \mathrm{ml})$ and Annexin-FITC $(5 \mu \mathrm{l})$, vortexed and kept for binding. After $30 \mathrm{~min}$, an additional $200 \mu \mathrm{l}$ binding buffer was added and the suspension was analysed on a FACS-Verse flow cytometer (BD Biosciences, San Jose, CA, USA $)^{[34,35]}$.

The process of apoptosis was investigated by staining the cells with Hoechst 33342 (Sigma, USA). Cells were seeded at the rate of $10^{5}$ cells/well in a 12 -well plate. After incubation for $24 \mathrm{~h}$, each well was treated with various samples, including free VRS, free DTX, free VRS/DTX combination, and VRS/DTX-LPH at $2 \mu \mathrm{M}$. Afterwards, the cells were rinsed twice with PBS and fixed in $10 \%$ formaldehyde PBS for $20 \mathrm{~min}$ at room temperature. Cells were washed again before staining with Hoechst 33342 for 15 min in the dark. The Hoechst 33342-stained nuclei were observed on a fluorescence microscope (Nikon Eclipse Ti) ${ }^{[36,37]}$.

\section{RESULTS AND DISCUSSION}

As VRS and DTX are both hydrophobic drugs, they can be carried on a lipophilic, biocompatible vehicle with a high loading capacity to amplify their activity ${ }^{[4,38,39]}$. In the past few decades, lipid carriers have proven 
an attractive option through the incorporation of hydrophobic agents into the lipophilic matrix as an effective delivery system into the body ${ }^{[40,41]}$. In this study, Capryol 90, TPGS, DDAB was used to dissolve VRS, as well as DTX, with a high entrapment efficiency $(73.7 \pm 2.1 \%$ and $75.8 \pm 6.8 \%$, respectively). The total content of the two drugs was $3.46 \%$ at a VRS/DTX molar ratio of 2:1. The ratio between the two drugs was selected owing to their biological synergism. In addition, the fabricated nanoparticles demonstrated favourable properties, such as small size $(232.4 \pm 5.8 \mathrm{~nm}$; fig. 1A), narrow distribution $(0.297 \pm 0.09)$, and negative charge $(-21.8 \pm 2.9 \mathrm{mV})$. The negative charge of formulated particles indicated the presence of PEG- $b$-PAsp on the surface of the nanoparticles. The PEG chain prolonged the residence of carriers in the blood stream by avoiding opsonisation from the macrophage system ${ }^{[42,43]}$. In addition, in the mimic acidic environment of tumours, PEG- $b$-PAsp undergoes protonation-deprotonation cycles and its protonation destabilizes the polymeric shell of $\mathrm{LPH}^{[14]}$. Consequently, VRS/DTX-LPH exposed the cationic core, which could interact with the negatively charged cell membrane to increase uptake into the endosome $\mathrm{e}^{[14]}$. The morphology of VRS/DTX-LPH was visible in the polymeric shell and the lipophilic core was seen in the TEM image (fig. 1B). Moreover, the estimated particle size and size distribution observed in morphological images were consistent with DLS results.

The XRD data of free VRS, free DTX, blank LPH, and VRS/DTX-LPH are shown in fig. 1C. Numerous sharp and intense peaks at various $2 \theta$ scattered angles indicated the highly crystalline nature of both drugs, whereas those characteristic peaks disappeared in the case of VRS/DTX-LPH. This absence could be explained by the transformation of drugs to an amorphous and molecular dispersion ${ }^{[4]}$. The transformed state of drug indicated the enhancement of drug distribution inside the lipid core via hydrophobic interaction, which could increase drug solubility and contribute to preservation of drugs for later release at the target site.

$\mathrm{pH}$-dependent release profile of the dual drugincorporated LPH (VRS/DTX-LPH) is presented in fig. 1D. Under equivalent conditions, the release rate of VRS was significantly faster than that of DTX $(\mathrm{p}<0.01)$.
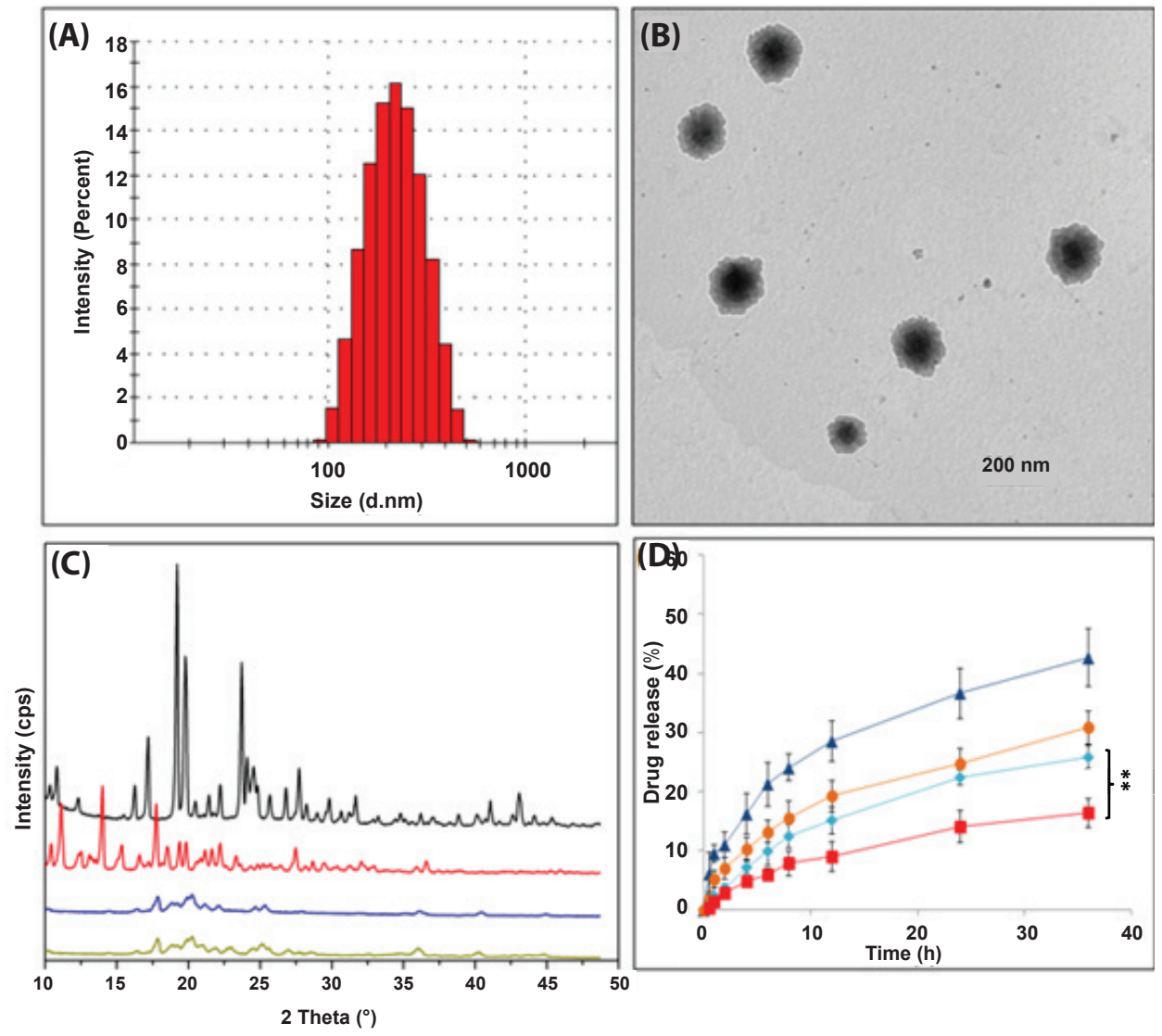

Fig. 1: Physical properties of VRS/DTX-LPH nanoparticles

(A) Particles size and distribution, (B) Morphological images, (C) X-ray diffraction patterns, (-) VRS; (-) DTX; (—) blank LPH; (-) VRS/DTX-LPH, and (D) in vitro drug release in ABS pH 5.5 and PBS pH 7.4, (- - -) VRS (pH 5.5); (-०—) VRS (pH 7.4); (- -) DTX (pH 5.5); (一匹-) DTX (pH 7.4). Data expressed as the mean \pm SD (n=3); **p-value $<0.01$ 
This could be attributable to the higher hydrophobicity of DTX $(\log \mathrm{P} \sim 3)$ than VRS $(\log \mathrm{P} \sim 2)^{[45,46]}$. In addition, there was a remarked increase in the percent VRS and DTX released from LPH in acidic conditions ( $\mathrm{pH}$ 5.5) compared to that released under normal physiological environment ( $\mathrm{pH} 7.0)$ after $24 \mathrm{~h}(\mathrm{p}<0.01$ in comparison of release percent in acidic and neutral $\mathrm{pH}$ of DTX). This phenomenon could be modulated by the protonation of the carboxylic group on the poly(L-aspartic acid) chains on the LPH surface ${ }^{[14,16]}$. Over 36 h, VRS and DTX were slowly released, approximately 42 and $25 \%$ release occurred at $\mathrm{pH} 5.5$, compared to 30 and $15 \%$ at $\mathrm{pH} 7.4$, respectively. The slower release in normal conditions may minimize the toxicity of anticancer drugs; conversely, once the drug was internalized into the endosome, additional release was triggered by the acidic environment. This strategy is considered as passively targeted drug delivery, enabling safer and more effective therapy.

The intracellular uptake of LPHs was characterized in vitro in three different cell lines (squamous cell carcinoma, SCC-7; human breast adenocarcinoma, MCF-7; human Caucasian breast adenocarcinoma, MDA-MB-231). Firstly, coumarin-6-loaded nanoparticles were incubated with cells to observe intracellular uptake using flow cytometry techniques. When the coumarin- 6 concentration was increased from 1 to $5 \mu \mathrm{g} / \mathrm{ml}$, the fluorescence intensity respectively increased in all cell lines, which demonstrated the increase of penetrated particles into cancer cells (fig. 2A). In addition, fig. 2B illustrated the accumulation of carriers in the cells after $15 \mathrm{~min}$, which indicated the rapid internalization that increased with an increase in incubation time (30 and $60 \mathrm{~min}$ ). Compared to the untreated cells, a remarkable increase in fluorescence intensity was recorded in all cell lines. Collectively, the data suggested that the uptake of carriers followed a time- and dose-dependent pattern.

The MTT assay was conducted to evaluate the effect of the individual drugs, drug combination, or drugs loaded into LPH on different cell lines. Most treatments resulted in a dose-dependent effect in which the cell viability was reduced when the concentration increased (fig. 3). Although the dose-dependent pattern was common to both drugs, the effect was not significantly different in MCF-7 and MDA-MB-231 when the cells were treated by DTX. This phenomenon could be explained by the resistance of breast cancer cells to Taxol through the escape of apoptosis pathways, efflux of the drug, or alteration of drug-binding sites ${ }^{[6,7]}$. Among the three
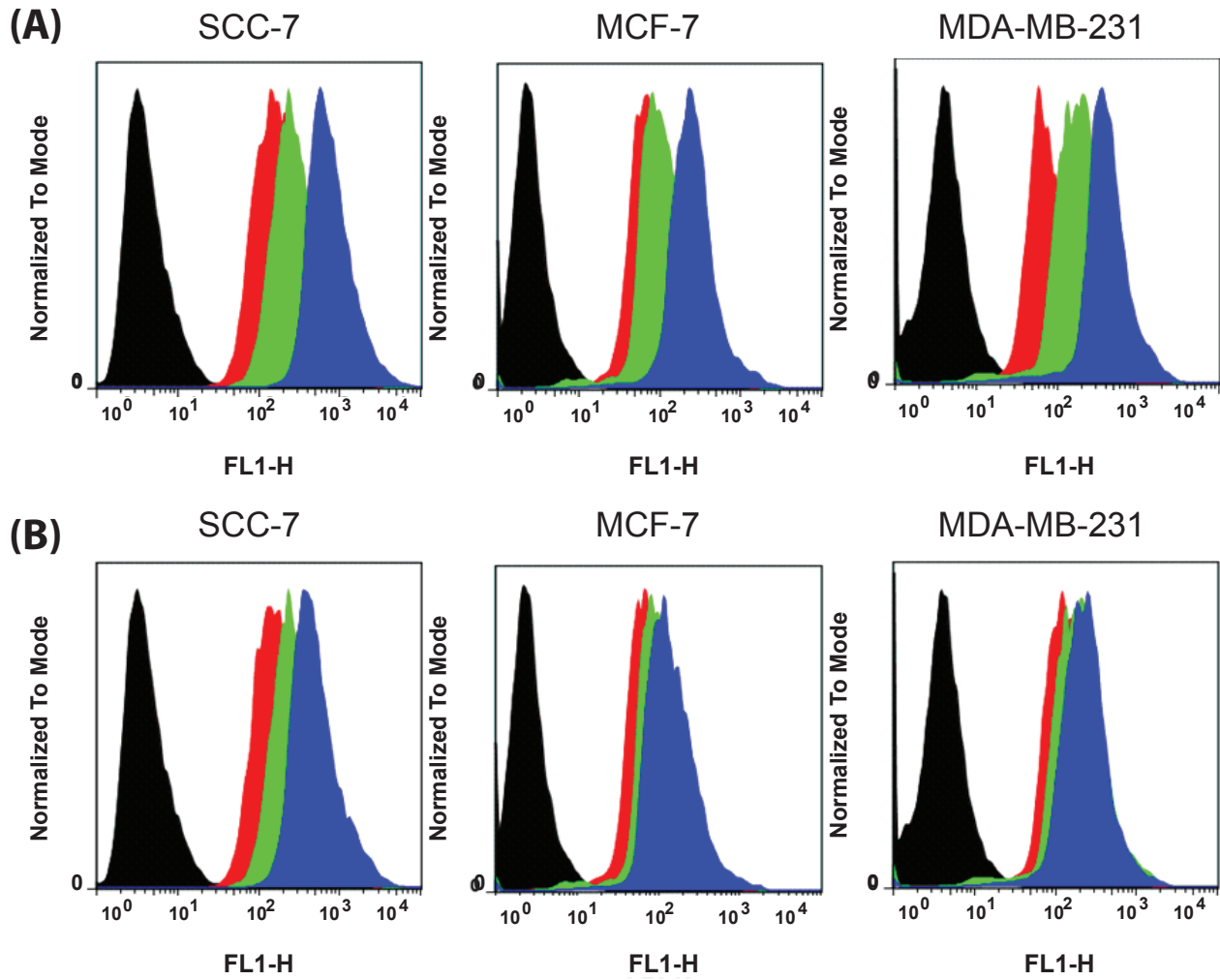

Fig. 2: Uptake of Cou-6-LPH nanoparticles as assessed by flow cytometry in SCC-7, MCF-7, and MDA-MB-231 Coumarin-6 uptake occurred (A) in a dose-dependent manner, (-) control; (-) $1 \mu \mathrm{g} / \mathrm{ml} ;(-) 2 \mu \mathrm{g} / \mathrm{ml} ;(-) 5 \mu \mathrm{g} / \mathrm{ml}$ and $(B)$ in a time-dependent manner, (-) control; (-) $15 \mathrm{~min}$; (-) $30 \mathrm{~min}$; (-) $60 \mathrm{~min}$ 
cell lines, MDA-MB-231 was the least sensitivity to both VRS and DTX. In detail, at concentration of $30 \mu \mathrm{M}$, the cell viability of MDA-MB-231 was $42.55 \pm 9.61 \%$ and $54.24 \pm 9.66 \%$ when exposed to VRS and DTX, respectively. Notably, at the same drug concentration, the cells treated with the VRS/DTX combination were significantly inhibited. To determine the synergistic effects of the combination, the data were analysed by CalcuSync software. After screening at various concentrations, the calculated $\mathrm{CI}$ for the SCC-7, MCF-7, and MDA-MB-231 cancer cell lines were, $0.469,0.698$, and $0.453(\mathrm{CI}<1)$, respectively, at a VRS/DTX ratio of 2:1, which indicated the synergistic effect of the VRS and DTX combination. Furthermore, in comparison with the individual
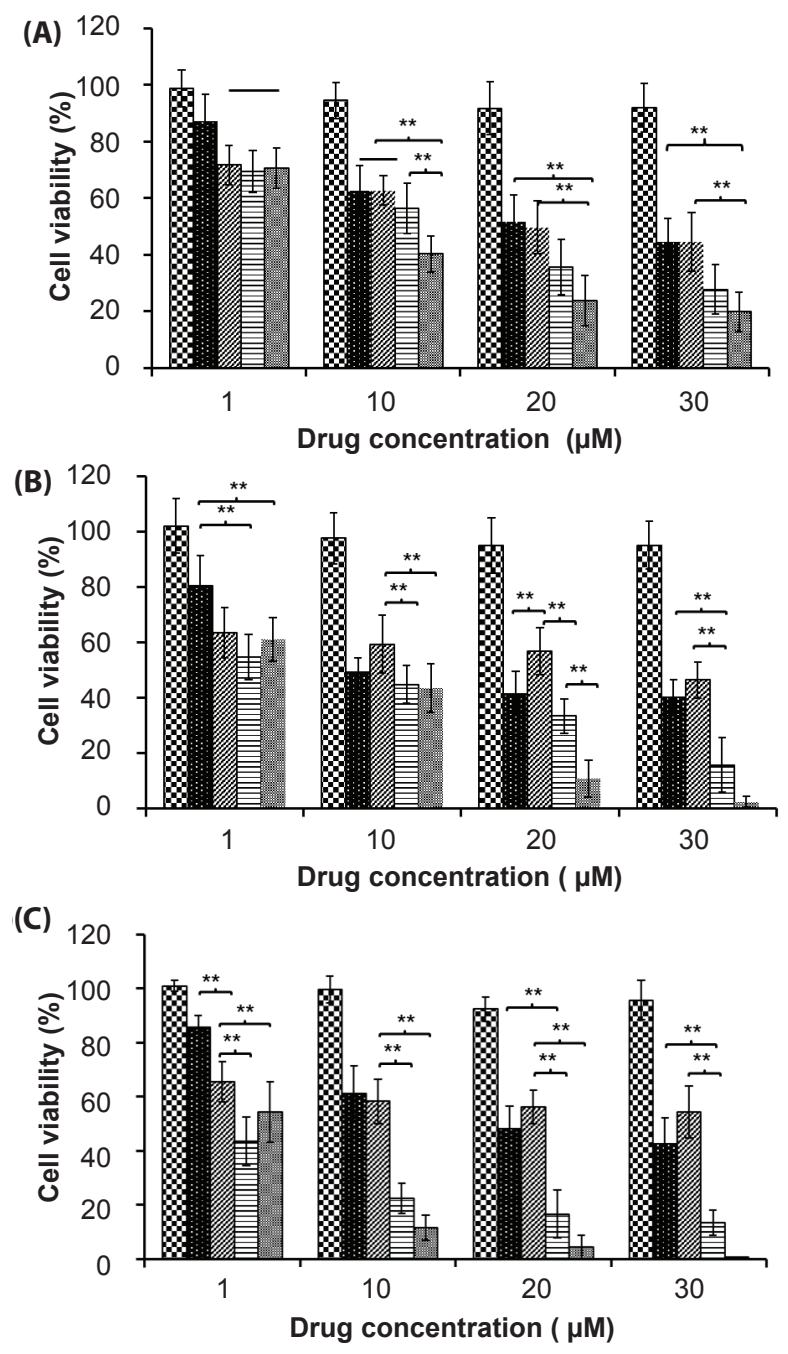

Fig. 3: In vitro cytotoxicity in SCC-7, MCF-7, MDA-MB-231 cells

In vitro cytotoxicity of 24 of exposure of blank LPH nanoparticles, free DTX, free VTS, VRS/DTX combination, and VRS/DTX-LPHs in (A) SCC-7, (B) MCF-7, and (C) MDAMB-231 cells (X) control; (圈) VRS; (吆) DTX; (三) VRS/DTX combination; (罪) VRS/DTX-LPH; data expressed as mean \pm SD $(\mathbf{n}=8) ; *$ p-value $<\mathbf{0 . 0 1}$ treatments, the combination of VRS and DTX induced higher cytotoxicity, especially in MDA-MB-231 cells. In contrast, in all three cell lines, the VRS/DTXLPH nanoparticles demonstrated better performance compared to the free individual drug or combination drug treatment. The small size and good internalization could contribute to the superiority of VRS/DTX-LPH. Moreover, interestingly, at a concentration of $1 \mu \mathrm{M}$, the free combined drugs achieved better activity. This could be attributable to the sustained release of drugs from the nanoparticles, which caused the effective concentration to be achieved much later.

Cellular apoptosis was assayed by flow cytometry to determine the changes of cells in the presence or absence of sample treatments (fig. 4). As shown in fig. 4, the control group for all cell lines, which were only exposed to media, showed negligible apoptotic and necrotic cells. In contrast, the apoptotic cell proportion was significantly increased after the treatment of free VRS, free DTX, or VRS/DTX-LPH. In terms of the free drug, VRS and DTX individually induced apoptosis in the treated cells; however, at a combination ratio $2: 1$, the number of observed early and late apoptotic cell was augmented. The data in MCF-7 cells clearly showed approximately $47 \%$ for VRS and DTX and $72 \%$ for the VRS/DTX combination. Similar results were obtained in SCC-7 and MDA-MB-231, although the differences were slightly smaller. In another comparison, the apoptotic study also was conducted for different concentrations and incubation times of VRS/ DTX-LPH. Among the drug-loaded LPHs, apoptosis was induced at a higher rate with higher incubation time or concentration, which was attributable to the enhancement of intracellular uptake. In comparison with the free VRS/DTX combination, cancer cells reproduced the apoptosis pattern underwent treatment of drug-loaded LPH, as indicated by a similar number of apoptotic cells. Those results were consistent with the intracellular uptake and in vitro cytotoxicity studies.

Finally, to determine the change in the morphology of cell nuclei that may occur in apoptosis, Hoechst 33342 staining was used. It is normal to see fairly smooth and homogenous nuclei, as in the case of untreated cells, but nuclear fragmentation and apoptotic bodies were detected in drug-treated cells (fig. 5). A bright blue fluorescent condensed nucleus was a feature of cells treated with VRS, whereas nuclear fragmentation tended to occur in cells treated with DTX. Both phenomena simultaneously observed in the cell-treated 


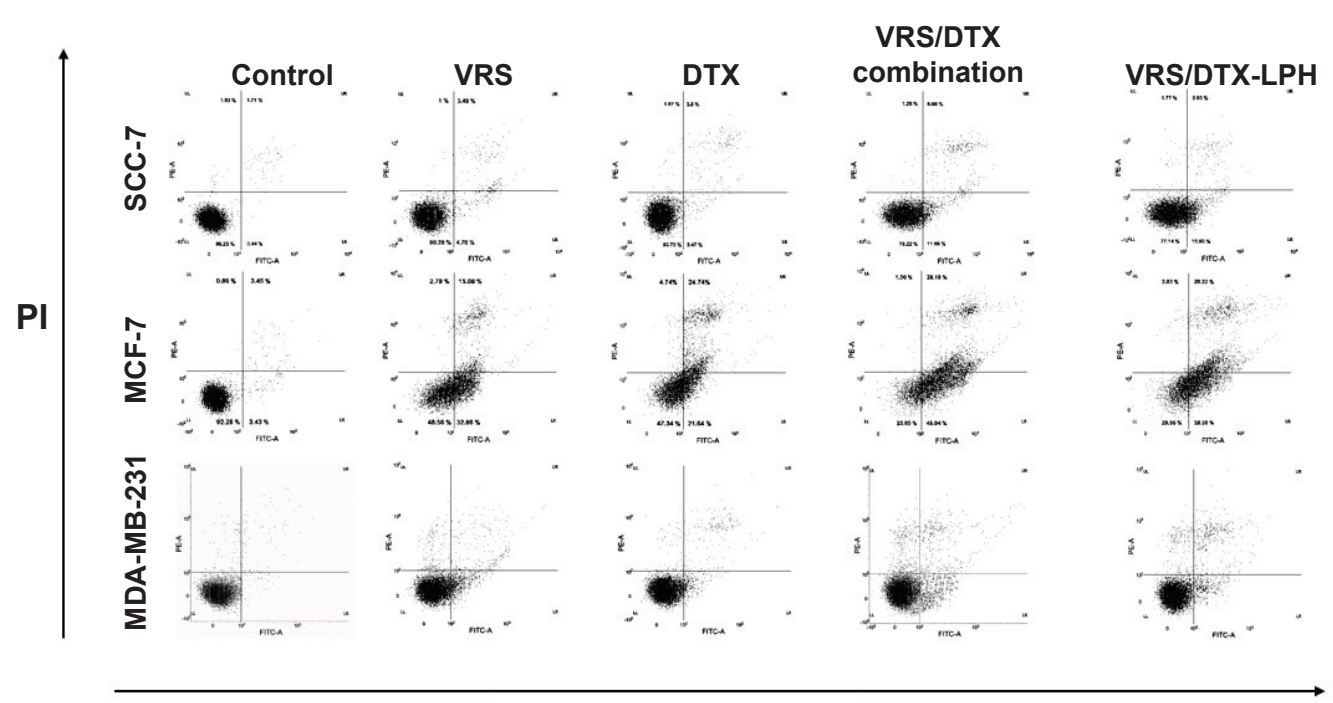

ANNEXIN V - FITC

Fig. 4: Cellular apoptosis under flow cytometry

Analysis of cellular apoptosis by flow cytometry after treatment for $24 \mathrm{~h}$ with $20 \mu \mathrm{M}$ each of free DTX, free VTS, VRS/DTX combination and VRS/DTX-LPHs

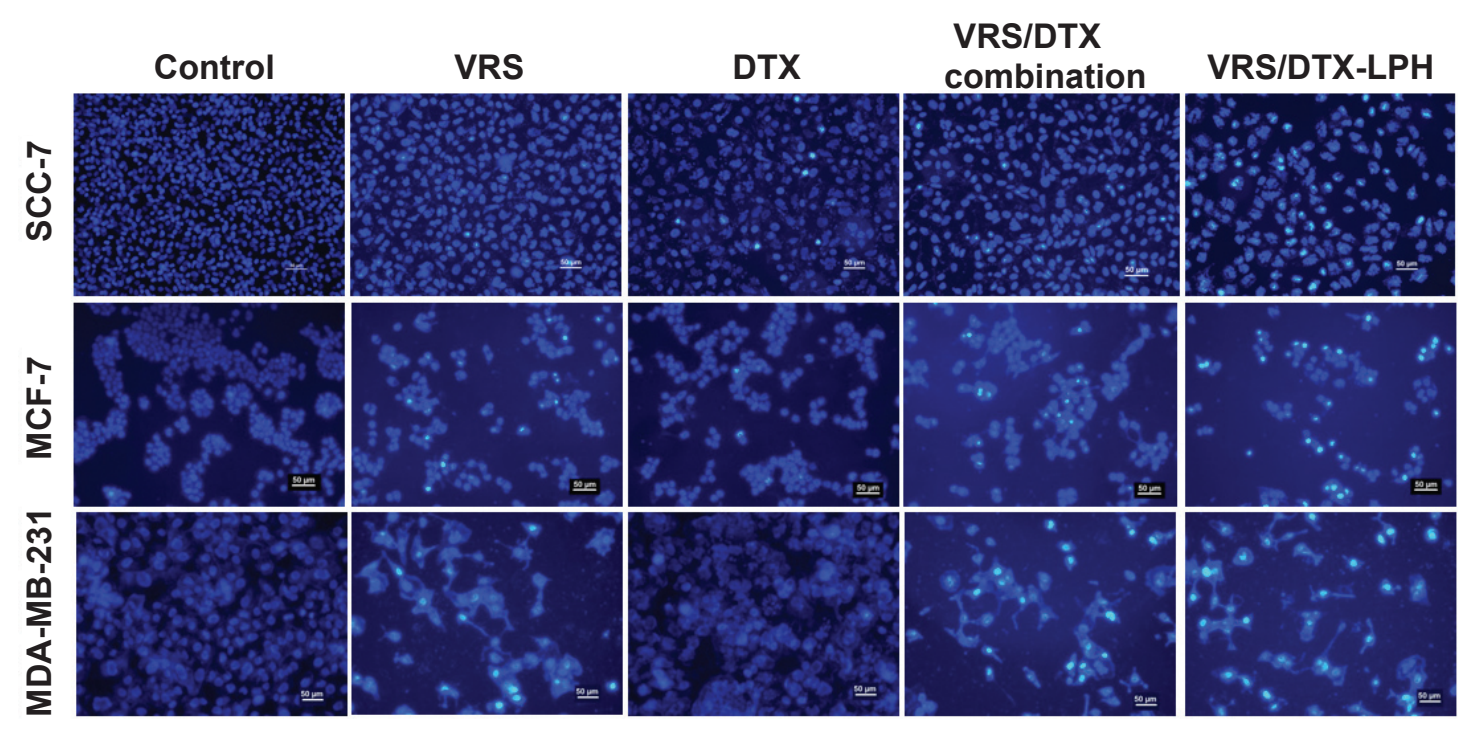

Fig. 5: Nuclear apoptosis under fluorescent microscopy

Nuclear apoptosis assay using fluorescent microscopy after treatment for $24 \mathrm{~h}$ with $2 \mu \mathrm{M}$ each of free DTX, free VTS, VRS/DTX combination and VRS/DTX-LPHs nanoparticles

combined drugs and optimized formulation. The specific mechanism at the molecular level indicated that VRS induced an augment in the expression of acetylated tubulin, which could enhance apoptosis and was also related to DTX activity ${ }^{[11]}$.

In summary, a simple drug delivery system for combination chemotherapy was developed. The nanoparticles of the VRS/DTX-LPH formulation were fabricated with a small size, high payload capacity, and the ability for controlled drug release. The welldesigned combination formulation greatly enriched the activity of individual drugs, through synergistic effects that were measured in the experimental data. These results demonstrated that the successful incorporation of VRS and DTX LPHs demonstrated the potential to overcome drug resistance and also improve the anticancer efficacy of chemotherapy.

\section{Acknowledgment:}

This research was supported by the Yeungnam University research grant in 2018.

\section{REFERENCES}

1. Youn YS, Kwag DS, Lee ES. Multifunctional nano-sized 
fullerenes for advanced tumor therapy. J Pharm Investig 2017;47:1-10.

2. Ferlay J, Soerjomataram I, Dikshit R, Eser S, Mathers C, Rebelo $\mathrm{M}$, et al. Cancer incidence and mortality worldwide: sources, methods and major patterns in GLOBOCAN 2012. Int J Cancer 2015;136:E359-E386.

3. Thapa RK, Youn YS, Jeong JH, Choi HG, Yong CS, Kim JO. Graphene oxide-wrapped PEGylated liquid crystalline nanoparticles for effective chemo-photothermal therapy of metastatic prostate cancer cells. Colloids Surf B Biointerfaces 2016;143:271-7.

4. Nguyen HT, Tran TH, Thapa RK, Pham TT, Jeong JH, Youn $\mathrm{YS}$, et al. Incorporation of chemotherapeutic agent and photosensitizer in a low temperature-sensitive liposome for effective chemo-hyperthermic anticancer activity. Expert Opin on Drug Deliv 2017;14:155-64.

5. Kastl L, Brown I, Schofield AC. miRNA-34a is associated with docetaxel resistance in human breast cancer cells. Breast Cancer Res Treat 2012;131:445-54.

6. Sprouse AA, Herbert BS. Resveratrol augments paclitaxel treatment in MDA-MB-231 and paclitaxel-resistant MDAMB-231 breast cancer cells. Anticancer Res 2014;34:5363-74.

7. Wang H, Vo T, Hajar A, Li S, Chen X, Parissenti AM, et al. Multiple mechanisms underlying acquired resistance to taxanes in selected docetaxel-resistant MCF-7 breast cancer cells. BMC Cancer 2014;14:37.

8. Ma X, Williams RO. Polymeric nanomedicines for poorly soluble drugs in oral delivery systems: an update. J Pharm Investig 2018;48:61-75.

9. Hu CMJ, Zhang L. Nanoparticle-based combination therapy toward overcoming drug resistance in cancer. Biochem Pharmacol 2012;83:1104-11.

10. Choi YH, Han HK. Nanomedicines: current status and future perspectives in aspect of drug delivery and pharmacokinetics. J Pharm Investig 2018;48:43-60.

11. Shi YK, Li ZH, Han XQ, Yi JH, Wang ZH, Hou ZL et al. The histone deacetylase inhibitor suberoylanilide hydroxamic acid induces growth inhibition and enhances taxol-induced cell death in breast cancer. Cancer Chemother Pharmacol 2010;66:1131-40.

12. Kastl L, Brown I, Schofield AC. Altered DNA methylation is associated with docetaxel resistance in human breast cancer cells. Int J Oncol 2010;36:1235-41.

13. Owonikoko TK, Ramalingam SS, Kanterewicz B, Balius T, Belani CP, Hershberger PA. Vorinostat increases carboplatin and paclitaxel activity in non-small cell lung cancer cells. Int J Cancer 2010;126:743-55.

14. Ramasamy T, Haidar ZS, Tran TH, Choi JY, Jeong JH, Shin $\mathrm{BS}$, et al. Layer-by-layer assembly of liposomal nanoparticles with PEGylated polyelectrolytes enhances systemic delivery of multiple anticancer drugs. Acta Biomater 2014;10:5116-27.

15. Sim T, Lim C, Hoang NH, Oh KT. Recent advance of $\mathrm{pH}-$ sensitive nanocarriers targeting solid tumors. J Pharm Investig 2017;47:383-94.

16. Kim JH, Oh YT, Lee KS, Yun JM, Park BT, Oh KT. Development of a $\mathrm{pH}$-sensitive polymer using poly(aspartic acid-graft-imidazole)-block-poly(ethylene glycol) for acidic pH targeting systems. Macromol Res 2011;19:453-60.

17. Ramasamy T, Ruttala HB, Kanu BG, Poudel BK, Choi $\mathrm{HG}$, Yong CS, et al. Smart chemistry-based nanosized drug delivery systems for systemic applications: A comprehensive review. J Control Release 2017;258:226-53.

18. Hashemi M, Omidi M, Muralidharan B, Tayebi L, Herpin MJ, Mohagheghi MA, et al. Layer-by-layer assembly of graphene oxide on thermosensitive liposomes for photo-chemotherapy. Acta Biomater 2018;65:376-92.

19. Hoang NH, Lim C, Sim T, Oh KT. Triblock copolymers for nano-sized drug delivery systems. J Pharm Investig 2017;47:27-35.

20. Nguyen HT, Tran TH, Thapa RK, Phung CD, Shin BS, Jeong $\mathrm{JH}$, et al. Targeted co-delivery of polypyrrole and rapamycin by trastuzumab-conjugated liposomes for combined chemophotothermal therapy. Int J Pharm 2017;527:61-71.

21. Jonsson-Schmunk K, Schafer SC, Croyle MA. Impact of nanomedicine on hepatic cytochrome P450 3A4 activity: things to consider during pre-clinical and clinical studies. J Pharm Investig 2018;48:113-34.

22. Nguyen HT, Thapa RK, Shin BS, Jeong JH, Kim JR, Yong $\mathrm{CS}$, et al. CD9 monoclonal antibody-conjugated PEGylated liposomes for targeted delivery of rapamycin in the treatment of cellular senescence. Nanotechnology 2017;28:095101.

23. Tran TH, Ramasamy T, Choi JY, Nguyen HT, Pham TT, Jeong $\mathrm{JH}$, et al. Tumor-targeting, $\mathrm{pH}$-sensitive nanoparticles for docetaxel delivery to drug-resistant cancer cells. Int J Nanomed 2015;10:5249.

24. Tran TH, Nguyen TD, Nguyen HV, Nguyen HT, Kim JO, Yong CS, et al. Targeted and controlled drug delivery system loading artersunate for effective chemotherapy on CD44 overexpressing cancer cells. Arch Pharm Res 2016;39:687-94.

25. Seo YG, Kim DH, Ramasamy T, Kim JH, Marasini N, Oh $\mathrm{YK}$, et al. Development of docetaxel-loaded solid selfnanoemulsifying drug delivery system (SNEDDS) for enhanced chemotherapeutic effect. Int J Pharm 2013;452:412-20.

26. Tran TH, Ramasamy T, Truong DH, Shin BS, Choi HG, Yong CS, et al. Development of vorinostat-loaded solid lipid nanoparticles to enhance pharmacokinetics and efficacy against multidrug-resistant cancer cells. Pharm Res 2014;31:1978-88.

27. Tran TH, Choi JY, Ramasamy T, Truong DH, Nguyen CN, Choi $\mathrm{HG}$, et al. Hyaluronic acid-coated solid lipid nanoparticles for targeted delivery of vorinostat to CD44 overexpressing cancer cells. Carbohydr Polym 2014;114:407-15.

28. Pham TT, Nguyen TT, Pathak S, Regmi S, Nguyen HT, Tran $\mathrm{TH}$, et al. Tissue adhesive FK506-loaded polymeric nanoparticles for multi-layered nano-shielding of pancreatic islets to enhance xenograft survival in a diabetic mouse model. Biomaterials 2018;154:182-96.

29. Thapa RK, Choi JY, Poudel BK, Tran TH, Pathak S, Gupta $\mathrm{B}$, et al. Multilayer-Coated Liquid Crystalline Nanoparticles for Effective Sorafenib Delivery to Hepatocellular Carcinoma. ACS Appl Mater Interfaces 2015;7:20360-68.

30. Ramasamy T, Ruttala HB, Sundaramoorthy P, Poudel BK, Youn YS, Ku SK, et al. Multimodal selenium nanoshellcapped $\mathrm{Au} @$ mSiO 2 nanoplatform for NIR-responsive chemo-photothermal therapy against metastatic breast cancer. NPG Asia Mater 2018;10:197-216.

31. Tran TH, Nguyen HT, Pham TT, Choi JY, Choi HG, Yong CS, et al. Development of a graphene oxide nanocarrier for dual-drug chemo-phototherapy to overcome drug resistance in cancer. ACS Appl Mater Interfaces 2015;7:28647-55. 
32. Ramasamy T, Kim JH, Choi JY, Tran TH, Choi HG, Yong $\mathrm{CS}$, et al. $\mathrm{pH}$ sensitive polyelectrolyte complex micelles for highly effective combination chemotherapy. J Mater Chem B 2014;2:6324-33.

33. Tran TH, Nguyen HT, Le NV, Tran TTP, Lee JS, Ku SK, et al. Engineering of multifunctional temperature-sensitive liposomes for synergistic photothermal, photodynamic, and chemotherapeutic effects. Int J Pharm 2017;528:692-704.

34. Chaudhari KR, Ukawala M, Manjappa AS, Kumar A, Mundada PK, Mishra AK, et al. Opsonization, biodistribution, cellular uptake and apoptosis study of PEGylated PBCA nanoparticle as potential drug delivery carrier. Pharm Res 2012;29:53-68.

35. Tran TH, Nguyen HT, Tran TTP, Ku SK, Jeong JH, Choi HG, et al. Combined photothermal and photodynamic therapy by hyaluronic acid-decorated polypyrrole nanoparticles. Nanomedicine 2017;12:1511-23.

36. Vivek R, Babu VN, Thangam R, Subramanian K, Kannan $\mathrm{S}$. pH-responsive drug delivery of chitosan nanoparticles as Tamoxifen carriers for effective anti-tumor activity in breast cancer cells. Colloids Surf B Biointerfaces 2013;111:117-23.

37. Nguyen HT, Phung CD, Thapa RK, Pham TT, Tran TH, Jeong $\mathrm{JH}$, et al. Multifunctional nanoparticles as somatostatin receptor-targeting delivery system of polyaniline and methotrexate for combined chemo-photothermal therapy. Acta Biomater 2018;68:154-67.

38. Tran TH, Chu DT, Truong DH, Tak JW, Jeong JH, Hoang $\mathrm{VL}$, et al. Development of lipid nanoparticles for a histone deacetylases inhibitor as a promising anticancer therapeutic. Drug Deliv 2016;23:1335-43.

39. Yan YD, Marasini N, Choi YK, Kim JO, Woo JS, Yong
$\mathrm{CS}$, et al. Effect of dose and dosage interval on the oral bioavailability of docetaxel in combination with a curcumin self-emulsifying drug delivery system (SEDDS). Eur J Drug Metabol Pharmacokinet 2012;37:217-24.

40. Gupta B, Yong CS, Kim JO. Solid matrix-based lipid nanoplatforms as carriers for combinational therapeutics in cancer. J Pharm Investig 2017;47:461-73.

41. Yoon G, Park JW, Yoon IS. Solid lipid nanoparticles (SLNs) and nanostructured lipid carriers (NLCs): recent advances in drug delivery. J Pharm Investig 2013;43:353-62.

42. Walkey CD, Olsen JB, Guo H, Emili A, Chan WC. Nanoparticle size and surface chemistry determine serum protein adsorption and macrophage uptake. J Am Chem Soc 2012;134:2139-47.

43. Sherman MR, Williams LD, Sobczyk MA, Michaels SJ, Saifer MGP. Role of the methoxy group in immune responses to mPEG-protein conjugates. Bioconjug Chem 2012;23:485-99.

44. Ramasamy T, Tran TH, Choi JY, Cho HJ, Kim JH, Yong CS, et al. Layer-by-layer coated lipid-polymer hybrid nanoparticles designed for use in anticancer drug delivery. Carbohydr Polym 2014;102:653-61.

45. Konsoula R, Jung M. In vitro plasma stability, permeability and solubility of Mercaptoacetamide histone deacetylase inhibitors. Int J Pharm 2008;361:19-25.

46. Son GH, Lee BJ, Cho CW. Mechanisms of drug release from advanced drug formulations such as polymeric-based drugdelivery systems and lipid nanoparticles. J Pharm Investig 2017;47:287-96. 